\title{
Implementation of Inclusive Education in Three Schools of Mthatha District in the Eastern Cape Province, South Africa
}

\author{
PJH Heeralal \\ Senior Lecturer, Department of Science and Technology Education, University of South Africa \\ P.O.Box 392, Unisa, South Africa \\ heerapj@unisa.ac.za \\ PP Jama \\ Pakamisa Junior Secondary School, P.O. Box 52731, Mthatha, 5099 \\ 41078497@mylife.unisa.ac.za
}

\section{Doi:10.5901/mjss.2014.v5n20p1500}

\section{Abstract}

This study investigated the implementation of inclusive education in three schools of Mthatha district in the Eastern Cape Province, in accordance with the principles set out in Education White Paper 6: Special Needs Education-Building an inclusive education and training system. The qualitative method was used in this study, and data collection strategies were based on interviews and observations. The study established the following challenges that hampered the implementation of inclusive education in the three schools: lack of training or workshops for both principals and educators on inclusive education, which led to a lack of knowledge about the topic and ways to support learners experiencing barriers to learning in their school and lack of access to the White Paper 6 document. These challenges can be remedied by proactive assistance from the Eastern Cape Department of Education and the Mthatha District of Education authorities.

Keywords: Inclusive education, White Paper 6, Implementation principles for an inclusive school, learning barriers.

\section{Introduction}

In July 2001, the South African Department of Education (DoE) published Education White Paper 6: Special Needs Education-Building an inclusive education and training system. This White Paper pointed out that the previous education system and curriculum under the apartheid government (prior to 1994) had generally failed to respond to the diverse needs of the learner population, especially those with learner disabilities, resulting in "massive numbers of dropouts, push-outs and failures" (DoE, 2001, p. 5). In the main, White Paper 6 outlined and defined an inclusive education and training system in terms of which it proposed a framework for establishing such a new system that would provide for special needs and support services. This system was to promote education for all, and to foster the development of inclusive and supporting centres of learning to enable all learners to participate actively in the education process. The chief purpose of these initiatives would be to develop and extend the potentialities of all learners so that they could participate as equal members of society.

Landsberg (2005) points out that education in South Africa entered a new era in 1994 with the advent of a truly democratic government. This brought about a new socio-political shift that emphasised important values such as equity, non-discrimination, liberty, respect, and social justice, which have provided the framework for the South African Constitution. The values embodied in the Constitution as the central, supreme law in the country were consequently also reflected in all other new legislative measures, including those concerning education. It therefore followed that major developments took place in the field of education in the years after the promulgation of the Constitution at the end of 1996 (South African Constitution, 1996), also in the area of inclusive education.

As could be expected, it was not only politico-legal changes that took place in education. According to Stofile (2004), the emphasis on inclusive education as a new reality in South Africa also brought about major philosophical shifts in the entire education system. Education White Paper 6: Special Needs Education set out to address the needs of all learners in a single, undivided education system, moving from the categorization of learners according to disability (a medical model) to assessing the needs and levels of support required by individual learners, with the aim of facilitating their maximum participation in the education system (DoE, 2005). This shift to inclusive education came as a response 
and commitment to the central tenets of the Constitution (South African Constitution, 1996) as reflected in various sections committing the state to certain principles: section 9(2), to the achievement of equality, sections 9(3), (4) and (5), to non-discrimination and section 29(1), to upholding the fundamental right of all citizens to a basic education.

The policy on establishing an inclusive education and training system adopts a social ecosystems perspective in that it shifts the focus away from locating problems within the learners to locating them in all systems that act as barriers to learning. These include the family, the school, and aspects of community functioning (Hay, 2003). In addition, the policy suggests a shift from focusing on the category of disability to the level of support needed by the learners identified during assessment (DoE, 2005b).

More than a decade has elapsed since the publication of White Paper 6 , and it is against the background of profound changes in the South African education landscape over recent years that the current study wishes to investigate a particular aspect in this landscape. Sufficient time has passed to allow for the implementation of inclusive education in some respects, and this study is aimed at examining the extent to which three secondary schools in Mthatha Education District in the Eastern Cape Province of South Africa have implemented the main principles of inclusive education. The principles that guide the broad strategies for realising the vision of inclusive education are summed up in paragraph 6 of the Executive Summary of White Paper 6 as entailing "acceptance of principles and values contained in the Constitution and White Papers on Education and Training; human rights and social justice for all learners; participation and social integration; equal access to a single, inclusive education system; access to the curriculum, equity and redress; community responsiveness; and cost-effectiveness" (DoE, 2001, p. 5). Carrying these principles into effect, in turn, entails the following strategies (as outlined by Engelbrecht, 2003):

- establishing institutional-level support teams (ILSTs) within each school, which will be aimed at facilitating provision for learners with special needs as stipulated in the South African Schools Act (No. 84 of 1996) mainly in terms of ensuring quality education for all;

- respecting the diversity of the learner population, which means acknowledging the rights of all learners to full participation in the learning and teaching process;

- promoting social integration, which implies the facilitation of opportunities for learners and other members of the learning community to learn and work together in a cooperative environment, and to address prejudices wherever necessary;

- nurturing an inclusive school environment, which involves the promotion of a general culture and ethos in the school that will reflect particular norms, values, and attitudes, particularly those oriented towards respect for diverse realities and needs, human relations, and the manner in which the school is managed; and

- supporting the curriculum, which involves all of its aspects, for example learning programmes, the medium of learning and teaching, and curriculum assessment.

\section{Purpose of the Study}

This study was aimed at investigating the measure of success achieved in the implementation of inclusive education in three secondary schools of Mthatha district in order to make appropriate recommendations to the Eastern Cape Department of Education (ECDoE), to educational officers of the Mthatha district and to school principals if the findings indicated that such recommendations would be required.

\section{Objectives of the Study}

The objectives of this study were to determine:

- what had been achieved in three secondary schools of Mthatha district in implementing inclusive education;

- the extent to which inclusive education principles had been put into practice in three public schools of Mthatha district;

- how inclusive education initiatives could be improved in three secondary schools of Mthatha district if the findings of the current study should indicate the need for this.

\section{Literature Review}

In order to arrive at an understanding of the importance of each strategy in the implementation of inclusive education in public schools, it was necessary to review the relevant literature on the aspects discussed below. 


\subsection{Brief overview of inclusive education in South Africa}

According to Stofile (2008), in order to understand the concept of inclusive education within the South African context, one needs to reflect on the history of special needs. Prior to 1994, the South African Department of Education was split into 18 racially divided sub departments that each had its own policies regarding learners with special needs. Not all of these education sub departments made provision for such learners, and disadvantaged communities in particular were marginalized.

At the beginning of 1997, the National Commission on Special Needs in Education and Training (NCSNET) and the National Committee for Education Support Services (NCESS) was appointed to investigate and make recommendations on all aspects of educational special needs and support services in South Africa (Stofile, 2008). This event may be regarded as the most important turning point in the history of South African education, following as it did on the country's first democratic elections and the subsequent framing of a Constitution that embodied fundamental human rights and freedoms. These values found expression in section (1) of the Constitution with regard to human dignity, equality and human rights, and in sections (9)(2), (3), (4), and (5) with regard to non-discrimination. White Paper 6 notes specifically that these basic values entail a special responsibility "to ensure that all learners, with and without disabilities, pursue their learning potential to the fullest" (DoE, 2001, p. 11). It also remarks on section 29(1), which commits the South African nation "to this fundamental right, viz. 'that everyone has the right to a basic education, including adult basic education ..."' (p. 11). In a certain sense, the ideals expressed in the Constitution (South African Constitution, 1996) may be regarded as a special challenge posed to the new nation by requiring that all learners must be given the opportunities to exercise their fundamental right to basic education. This meant that the imbalances of the past had to be redressed by focusing on key issues of equity and access to education as the most important instruments of self-empowerment.

Even before the advent of democratic elections, influential reports emerged between 1990 and 1994 that strongly recommended a move towards the establishment of a unitary education system for South Africans (ECDoE, 2008). After that period, increasing emphasis was laid on the crucial importance of inclusiveness in the new educational system because of its function of recognizing and respecting differences among all learners, educators, and the system as a whole, but "building on the similarities" (DoE, 2001, p. 17) so that the full range of learning needs could be met.

\subsection{Inclusive education policy}

In order to achieve inclusive education, Education White Paper 6 served as one of the foundation stones of South Africa's new education policy. This policy declares in its proposals, recommendations, and strategies the intention to transform the education system into one that effectively responds to and supports learners, parents, and communities by advocating the removal of all barriers to learning existing in the education system (Da Costa, 2003). As a policy document, the White Paper outlines six strategies or levers for establishing an inclusive education system:

the implementation of a national advocacy information programme in support of the inclusion model;

the qualitative improvement of special schools for the learners whom they serve;

the conversion of approximately 500 mainstream primary schools to full-service schools;

the establishment of district-based support teams (DBSTs) and institutional-level support teams (ILSTs) to provide coordinated professional support to special and other schools;

the general orientation and introduction of management, governing bodies, and professional staff to the inclusive education model; and

the mobilization of approximately 280000 disabled children and youth of compulsory school-going age who are currently outside the school system (Stofile \& Green, 2004).

\section{Methodology}

This study followed a qualitative approach because it facilitates an in-depth investigation into and understanding of a specific situation, which in the case of the current study was the implementation of inclusive education in three secondary schools of Mthatha district in the Eastern Cape Province. A qualitative research approach is frequently accompanied by a case study design, and this study is no exception. A case study design entails an in-depth analysis of a single experience or entity (McMillan, 2008). This implies that a single aspect could be the object of investigation, although it may assume a multiple form, for example a certain facet of something at different locations. Case study design was chosen because, as outlined by Lauer (2006), it is a flexible form of enquiry best suited for studying a particular phenomenon.

The phenomenon at issue in the current study was the implementation of inclusive education in three secondary 
schools in the Mthatha district. Interviews were held with principals and teachers (educators) as they were informationrich key informants concerning the implementation of inclusive education because they served as designated implementers of the policy. Data were collected through these interviews, which can be defined as surveys that were administered verbally, either individually or in groups, using structured, semi-structured, or unstructured protocols as specified by Lauer (2006). Semi-structured interviews were chosen because they allowed the researcher to obtain information in the form of verbal and non-verbal responses of participants. Simultaneously, the semi-structured interview approach had the advantage of using a few set questions for eliciting the maximum information yield in terms of probing and prompting participant responses.

\subsection{Data collection techniques}

As pointed out by McMillan and Schumacher (2006), data collection strategies are ways of acquiring useful information on what is being researched. In this study, interviews were the first technique used to acquire data because of their characteristic of being a flexible tool for data collection through permitting the use of multi-sensory channels: verbal, nonverbal, spoken, and heard (Louis, Manion, \& Morrison, 2007). Semi-structured or non-directive interviews were employed where the interviewer had a few set questions or prefigured frameworks that allowed for probing and prompting, pressing for clarity and elucidation, rephrasing and summarizing where necessary, and checking for confirmation of this, particularly if issues were complex or vague (Louis et.al, 2007).

\section{Findings}

\subsection{Themes Based on Interviews with Principals}

Principals were provided with a list of questions beforehand so that they could familiarize themselves with the content of the interview. Some additional questions were posed during the interview, but they served the purpose of prompting and probing to obtain clarification about obscure or individual meanings.

\subsubsection{Understanding of inclusive education}

Although all three principals revealed an understanding of inclusive education as reflected in their answers to the set questions, it appeared that this understanding was more limited than it should have been. It may be assumed that since principals are representatives of the DoE in schools, they can be considered the first ones to know about any policy. Therefore, as overseers of its implementation, it is expected of them to be aware of any challenges that are experienced in such implementation, and they should be responsible for providing guidance and recommendations on what needs to be done.

The DoE (2001) and Clough \& Corbet (2000) define inclusive education as a process not merely about providing access to mainstream schools for learners who have previously been excluded, but also about acknowledging that all children and youth can learn and that all children and youth need support. Considering that this assumption entails a deeper level of understanding of the fundamentals of inclusive education, it appeared that such perception was absent in the views of principals, perhaps because of a difference in emphasis on what should be considered fundamental and what not. This corroborates the findings of Wildeman and Nomdo (2007) that, across all provinces in South Africa, there were different perceptions about what inclusive education entailed or meant and how it should be implemented.

\subsubsection{Implementation of inclusive education in schools}

Two principals were of the view that inclusive education implementation would be successful in the district, but remarked on the following lacks that their district had to deal with:

- disability-friendly infrastructure;

- training of educators in inclusive education; and

- training for principals and parents concerning inclusive education.

This supported the findings of Ngcongo and Chetty (2006) who maintain that every public school is legally compelled to implement policies outlined in a DoE document that clearly stresses that every public school is a juristic person with legal capacity to perform its functions in terms of the South African Schools Act (Act No. 84 of 1996), section 12(15). One principal was of the view that Mthatha was not ready to implement inclusive education as nothing had been 
done to improve infrastructure for accommodating learners with barriers, more especially physical barriers experienced by the mobility and visually impaired.

\subsubsection{Inclusive education implementation in individual schools}

Although learners with barriers were already present in the classrooms in all three schools, one principal responded in the negative to the question whether the school was already implementing inclusive education and explained that teachers had not yet been trained. The other two principals replied in the affirmative, but also complained of lack of training for educators who already had to cope with a heavy workload. Considering that inclusive education is a process not merely about providing access to mainstream schools for pupils who have previously been excluded, it is acknowledging that all children and youth can learn and that all youth and children need support (Clough, 2000; DoE, 2001).

If educators who are supposed to give support are not trained, as the responses of principals about inadequacies in training indicate, it appears that in all these schools actual implementation of inclusive education has not yet been done. Howell (2007) is of the view that while removing barriers to accessing basic education is extremely important in addressing the inequalities of the past for learners with special needs, gaining entry is not enough to ensure that these learners are able to participate equally in the education system.

School development programme on inclusive education implementation

Without exception, the principals reported that they did not have such programmes because before they would be able to introduce their own, the DoE should empower educators through workshops on the issue or policy of inclusive education. They all noted that they referred learners with barriers to medical practitioners and some to special schools, whereas others, for example those with hearing difficulties who were supplied with appropriate aids, remained in their schools. This is contrary to the fundamental purpose of inclusive education, namely to facilitate access to the curriculum for learners experiencing impairments. A further basic requirement is to emphasise and support the paradigm shift from the previous medical model of disability (which is based on the premise that impairment is within a learner who has to "change" to fit into the education system) to a socio-critical model that is based on the premise that society must change to accommodate the diverse needs of all its people.

\subsubsection{Conceptual knowledge}

All of the principals revealed deficiencies in a thoroughgoing knowledge of inclusive education. Even though they demonstrated some knowledge by being able to define the general concept, regarding the finer terms and specifics of White Paper 6 they had never attended any formal workshop where they were addressed on more subtle aspects. Moreover, their school mission statements cited inclusive education as a tenet, but in practice it was not being carried into effect. It was mentioned that one of the reasons for selecting principals as participants was that they served as representatives of the DoE in schools. As such, they were the ones to know of any change in the curriculum or education affairs as directed by the DoE, and would consequently be responsible for introducing any changes to their staff and monitoring all implementations.

\subsubsection{Access to White Paper 6}

None of the three principals was in possession of the inclusive education document White Paper 6 . Consequently, they did not know what it involved and in their responses noted that they had to assume what it might imply. This also served as an indication that in these three schools inclusive education had not yet been introduced, let alone being implemented. White Paper 6 as a policy document "provides a framework for systemic change where strategies are oriented towards building the capacity of the system to respond to the full range of barriers to learning, including disabilities that exist among children in the country" (Howell \& Lazarus, 2003; p. XX), and, as this quotation signifies, it is imperative for each school to have a copy of White Paper 6 and study it in depth.

\subsection{Interviews with Educators}

The responses from educators were analysed and grouped as themes. 


\subsubsection{Presence of learners with barriers in their classrooms}

The DoE (2005) defines barriers to learning as difficulties that arise within learners themselves, in the education system as a whole, or in the learning site, preventing both the system's and the learners' needs from being met. All nine educators from the three schools confirmed that they already had learners with barriers in their classrooms. Among the barriers specified were reading, writing, slow learning, hearing, and visual impairments. None of the educators considered the system of education to be a barrier, as was indicated in (DoE, 2005). All educators cited those barriers within learners themselves as if still exclusively following the medical model, which, although helpful in explaining one facet of the framework for inclusion, fails to take account of the right to education of all learners, regardless of their individual characteristics or difficulties. A medical model labels and places each learner in a specialized school depending on the barrier, which is not the case with inclusive education.

\subsubsection{Lack of school support to educators}

All of the educators remarked that they obtained no support from their schools concerning how to assist learners with barriers to learning. Principals also confirmed that the schools provided no support to educators since they as principals were not sufficiently informed about inclusive education themselves to be able to provide guidance. Some educators noted that the only assistance they obtained was from experienced colleagues, which implied that such help was based on past practices and not on the new inclusive approach advocated in White Paper 6. Others stated that they informed the School Management Team (SMT)about learners experiencing barriers, after which the SMT usually referred such learners to special school as they saw fit, which was not different from what used to be known as exclusion of these learners.

\subsubsection{Lack of inclusive education knowledge}

In one school, educators who had been on its staff for more than five years claimed to have an ILST functioning there, but another educator who had been on the staff for less than three years professed never to have heard of it. All nine educators at the three schools acknowledged that they had learners with barriers to learning in their classrooms, but it could be assumed that these learners did not acquire learning at the level of their peers because of a lack of inclusive education knowledge in their educators.

As the establishment of an ILST is also one of the main requirements for an inclusive school, the schools of this study-despite having learners experiencing barriers-were not implementing inclusive education as they should. The point of qualifying as an inclusive school, and indeed the point of inclusive education in its entirety, is not merely to have learners with barriers to learning placed in mainstream schools (the phenomenon of "tokenism"), but to ensure that they have access to and acquire learning at the quality level of their peers (DoE, 2001).

\subsubsection{Learner support}

All nine educators asserted that they did indeed support learners experiencing barriers to learning by providing extra tuition, placing some learners in the front of classes, asking other teachers in the phase to assist, and referring learners for support from special schools. The DoE (2001) maintains that support services within all education rest on strengthening DBSTs to evaluate programmes, diagnose their effectiveness, and suggest modifications. Engelbrecht (2003) states that it is important to recognize that the practicalities of adapting classrooms to accommodate the learning needs of all learners have fallen mostly on class teachers. Teachers are consequently in need of empowering workshops on handling difficult situations so as to enable them to cope. Failure of taking the systemic variables into account in both the analysis of and interventions in these situations leaves the teacher in a situation where trial-and-error strategies lead to more confusion, conflict, and stress. Based on what these educators do to support learners with barriers to learning, it is clear that it is trial and error which may lead to conflict and stress because there is no clear direction as to how to support these learners who are already in their classrooms (Engelbrecht, 2003).

\subsubsection{Conceptual knowledge}

Swart and Pettipher (2007) maintain that research in South Africa, as in other countries, indicates that teachers play one of the most influential roles in the successful implementation of inclusive education. However, from the responses of 
educators in this study regarding their knowledge of inclusive education, it appeared that although some of them claimed to be familiar with basic concepts such as ILST, they did in fact have only a tenuous grasp of even the main concept of inclusive education itself. Only one educator knew these concepts because she was enrolled for an Advanced Certificate in Education (ACE) with specialization in inclusive education. She made the significant observation that even though she was familiar with the principles of inclusive education, it was difficult to apply them in a classroom situation because of a high workload.

\subsubsection{Presence of support resources}

Booth \& Ainscow (1998) (as cited in Engelbrecht, 2006), maintains that schools should be at the centre of support aimed at enhancing the capacity of individual schools to promote the participation and learning of an increasing diverse range of learners. All the participating educators in this study noted that they did not have many resources to support them, except for charts provided to some of them. Such deficiencies underscore Engelbrecht's (2006) view that lack of resources and lack of institutional capacity (both in administrative systems and in suitably trained teachers) constrain the successful implementation of new education policies.

\section{Discussion of Findings}

The researcher categorised the data in accordance with recurring topics that emerged from the interviews with principals and educators, from which themes were then formulated. The data for this study strongly indicated that the participating teachers, who had experience only in what may be termed "general education" and despite lacking any training in inclusive education, were nevertheless positive in their endeavours to provide support to learners experiencing barriers to learning in their classrooms

\subsection{Presence of barriers in the classrooms}

The information obtained in this study from both principals and educators of the three schools revealed the presence of learners with barriers to learning, among which visual, hearing, slow learning, and poverty barriers were the most important categories.

\subsection{Lack of school support to educators}

Six interviewed educators from two schools said that they did not get support from their schools to help learners experiencing barriers to learning. Three educators from one school also noted they did not receive support but that the SMT referred such learners to appropriate special schools. Engelbrecht (2006) observes that NCSNET/NCESS Report recommendations were largely phrased in the language of human rights, which differs radically from that of the medical model. From the findings of the current study, it was clear that the principals could not provide support to an initiative with which they were not familiar. Since they asserted that they lacked clarity on what inclusive education entailed, and were therefore unaware of what was expected of them, they were at a disadvantage about how to implement it in mainstream schools.

\subsection{Lack of departmental support to principals}

Interviewed principals cited the fact that they did not receive any support from the district officials, as they had never been invited to any workshop on inclusive education. The only relevant information they could obtain was from other sources such as specializations in university curriculums. They had no required document on inclusive education in their possession, not even the fundamentally important White Paper 6 . Some of them had to make assumptions about what the White Paper might contain, as they had never heard of it. It appears that the DBSTs may have failed to fulfil its function in this respect, as one of its duties is to empower schools in the establishment of ILSTs and to see to it that they function well.

\subsection{Lack of inclusive education knowledge}

The responses from the interviewed principals and educators indicated that they lacked knowledge on inclusive 
education. The principals, for example, were not certain what White Paper 6 entailed, whereas several of the educators were unfamiliar with concepts such as ILST. In the cases where educators were listed as ILST members, they did not know what their duties involved.

\subsection{Lack of resources}

In all three schools, the principals indicated that there were no resources for inclusive education. Even a fundamental prerequisite such as White Paper 6, the policy document for inclusive education at all levels of the education system, was not available to them. Educators also pointed out that they had no inclusive education resources on how to help learners experiencing barriers to learning. Support was so meagre that, for instance, they were obliged to design their own charts to aid learners with visual learning barriers.

The principals further indicated that infrastructure in their schools was not catering for inclusivity. For example, there were no ramps for children using wheelchairs. These principals also admitted that their schools had not yet started being inclusive in nature, even though learners experiencing barriers to learning were already present in their classrooms.

\subsection{Inadequacies in the support from district level}

Yet another deficiency remarked upon by all the principals was that no workshop had been arranged in the district to prepare and equip them for inclusive education. Educators from the three schools confirmed this lack of workshop assistance, with the exception of a single workshop that they could remember in 2009, but to which only one educator per school had been invited. That particular workshop was supposed to serve as an introduction to inclusive education, and the expectation arose that it would be followed by other workshops which would involve all educators. Some of the educators assumed that they would receive instruction and guidance in inclusive education and how to provide support to learners experiencing barriers to learning, similar to other occasions when changes in the curriculum had been introduced. The only support received from the district level, as mentioned by one school, was the provision of a hearing aid for one learner, whereas another was referred to a special school. In such instances of support, there was no followup from the district to discover what other barriers the schools experienced, to provide guidance in how do to deal with them, and to start equipping educators for managing them.

\subsection{Challenges in implementing inclusive education}

All participants-principals and educators-affirmed that they had had no formal introduction to inclusive education, which is why they found it difficult to be of help to those learners with barriers to learning who were already in their classrooms. Other educators mentioned the following as challenges:

(a) Lack of training in inclusive education: Faller (2005) has remarked on inadequate training of teachers (in South African context), noting that universities are ill-equipped to provide adequate teacher training programmes for all school phases. Scrugg and Mastropieri (as cited in Landsberg, 2005) maintain that for inclusive education teaching, teachers need systematic and intensive training, either as part of their initial training by competent and experienced people.

(b) Unfamiliarity with all barriers to learning: Educators in all three the schools stated that they had learners with barriers in their classrooms, but since they were not trained in assessing barriers they were able to recognize only those ones that were easily detectable and tried to support them. An additional exacerbating factor in South African schools is that of the HIVIAIDS pandemic, which in Cohen's (2002) view is not only eroding the capacity of the education sector to meet its core objectives of providing quality education for all, but is placing demands on schools and ultimately on teachers that they are incapable of managing. Prinsloo (as cited in Landsberg, 2005) lists the following issues that give rise to severe barriers in the provision of quality education for all children in the country:

- the culture of poverty with its resultant underdevelopment, environmental deprivation, unplanned urbanization, unemployment, and negative expectations of the future;

- the disintegration of family life;

- the effects of the decline of moral and value systems;

- the climate of violence and child abuse in contemporary South Africa;

- the HIVIAIDS pandemic and its effect on the learning climate; and 
- language and cultural differences.

In view of the above, there could be large numbers of learners who may be experiencing these barriers. However, because the barriers are not of a physical nature, the learners affected by them are not regarded as having any barrier.

(c) High workload: One principal remarked that even though he had an educator on his staff who could help other educators since she was familiar with the principles of inclusive education, their school was a secondary one that catered for Grades R-9 whereas the full staff complement consisted of only nine persons. He explained that because the staff establishment was based on learner enrolment numbers and not on provisioning for learning areas, this left educators overloaded.

(d) Other challenges: Some other important challenges that have already been touched upon above were the following:

- inclusive education had not been introduced to educators and even to principals;

- the school infrastructure was not user-friendly for learners with special needs;

- there was a lack of support and resources.

In reply to the research question about the extent to which inclusive education had been implemented in these three schools, it appeared that significant or even serious deficiencies existed not only in theoretical understanding, but consequently also in practical implementation. Little appreciation existed for the important principle that learners with barriers are expected not to be side-lined but to be supported, to be part of the class not in body only but also in the acquisition of learning. The fundamental weakness, as noted in this study, was that the implementation of inclusive education in these three schools could not be considered to be even in its initial stages, although learners with barriers to learning were already present in their classrooms. The existence or presence of learners with barriers in mainstream schools does not necessarily make these schools inclusive in nature. It may be considered ironical that prior to 1994, learners with barriers to learning did indeed attend mainstream schools, but it was in these schools that they were identified to have barriers, labelled, and sent to special schools after diagnosis. The consequence was that of being sidelined or overlooked until the system would leave them by the wayside as drop-outs.

The characteristics of an inclusive school pointed to the crucial difference between the former apartheid and the current inclusive systems. In the latter system, learners with barriers to learning have unfettered access to mainstream schools, but the difference is that every effort is made to retain them there. However, a subtle hazard still exists for such learners and educators. As implied in the previous paragraph and noted earlier in this study, to have these learners in mainstream classrooms does not necessarily mean that a school is inclusive. A school that professes to practise inclusive education can only truly lay claim to this distinction if it fully adheres to the principles of inclusive education as set out in White Paper 6 and actually carries those principles into effect. The danger that all in the field of inclusive education should guard against is that of lip-service.

In an evaluation report of two pilot projects for inclusive education, SCOPE and DANIDA Da Costa (2003) noted that while an inclusive education policy was considered to be an appropriate strategy for addressing the diverse needs of all learners in South Africa, its implementation was complex. Even though it has been nine years since the publication of Da Costa's study, this conclusion can only be confirmed by the findings of the current study. For example, the complexity of the implementation of inclusive education was reflected in the difficulties experienced by the principals who were dependent on the district, which in turn was dependent on the province. Wilderman and Nomdo (2007) also confirmed that there was an absence of a common understanding when it came to inclusive education. The findings of their study across the provinces of South Africa indicated that different perceptions existed about what inclusive education meant and how it should be implemented. Furthermore, the study conducted by Da Costa in the Mpumalanga and Northern Cape provinces of South Africa revealed a gap at all levels of the education system between the conceptualization of inclusive education and its implementation. Such a gap was one of the major phenomena evident from the findings of the current study.

\section{Recommendations}

The recommendations presented here are based on the findings discussed. The DoE (2001) stated that the primary function of DBSTs would be to evaluate and, through supporting teaching, build the capacity of schools, early childhood and adult basic education and training centres, colleges, and further and higher education institutions to recognize and address severe learning difficulties and to accommodate a range of learning needs. Based on the above, the following recommendations may be submitted to the ECDoE:

Personnel familiar with inclusive education should be employed and workshops should be presented to district staff 
in particular to ensure that DBSTs are established. Moreover, members of DBSTs should be trained in what is expected of them, and their effectiveness should be monitored (e.g., via their submission of reports) to detect challenges and measure successes experienced in implementing inclusive education.

Mthatha district personnel should present workshops on inclusive education to principals and educators. The DoE (2006) considers it to be a strategic initiative of DBSTs to engage in the general orientation and introduction of management, governing bodies, and professional staff to the inclusive education model. DBSTs should furthermore concentrate on the targeting and early identification of learners with barriers to learning so that appropriate interventions can be instituted in the foundation phase.

DBSTs have to ensure that there is a clear understanding in schools about ILSTs, especially regarding their membership and duties.

It is essential that schools should be provided with copies of White Paper 6, which serves as the key document on inclusive education and its implementation principles.

Educators who identify learners with barriers to learning in their classrooms have to be provided with training and resources on how to provide assistance to such learners.

Educators who are knowledgeable about inclusive education, for example because of having specialized in it in their studies, should be identified by district personnel and have their normal workload appropriately reduced so that they can introduce, establish, and implement inclusive education in their own and neighbouring schools.

All schools in the district should be provided with the particulars of DBST members so that they can be contacted when the need arises for assistance in inclusive education programmes.

Schools have to ensure that learning is accessible to every learner admitted, despite any barriers to learning that a particular learner may be experiencing. This can be achieved by enquiring from the DoE what needs to be done if such a learner is already in the classroom.

Principals should be in earnest about the commitment expressed in their schools' mission statements on admitting all learners regardless of any barrier to learning that they are experiencing. Because of the crucial importance of the stipulation that all learners have a right to be admitted and also to learn, it is incumbent on principals to inform the relevant department of education about learners with learning barriers so that further steps can be taken to support such learners. This is a core commitment based on the principle that all learners and youth have the ability to learn (DoE, 2001).

Finally, educators should also be proactive in taking the initiative whenever they identify a learner with a barrier to learning in their classrooms. For smooth running of any school, there are committees that are equipped to deal with particular problems, among other things to help learners with barriers to learning. Such a committee is the one to communicate with the SMT on the matter, even going as far as the district office to seek for help. Educators should not allow themselves to fail in their commitment to ensuring that the classroom is a place where every learner should be enabled to acquire learning.

\section{Conclusion}

The research findings of this study indicate that the implementation of inclusive education in three secondary schools of Mthatha district cannot be considered to have started in spite of learners with barriers to learning being enrolled in them. Various challenges can be cited for this deficiency, but it appears that a lack of support from DBSTs is a crucial factor.

\section{References}

Booth, T. \& Ainscow, M. (Eds.) (1998). From them to us: An international study of inclusion in education. London: Routledge. Retrieved from: www.questia.com.

Clough, P. \& Corbet, J. (2000). Theories of inclusive education: A student guide. London: Paul Chapman.

Cohen, L., Manion, L. \& Marrison, K. (2000). Research methods in education (5th ed.). New York: Routledge.

Da Costa, M. (2003). Opening schools for all children in South Africa: The experiences of inclusive educational needs in Mpumalanga and Northern Cape Provinces. United Kingdom: South African-Finnish Cooperation Programme in the Education Sector.

De Coning, C. (2002). Peacekeeping in Africa. African journal of conflict resolution, 4(1). pp.55-62.

Department of Education. (2001). Education White Paper 6: Special Needs Education-Building an inclusive education and training system. Pretoria: Government Printers.

Department of Education. (2005a). Guidelines for inclusive learning programmes. Pretoria: Government Printers.

Department of Education. (2005b). Conceptual and operational guidelines for the implementation of inclusive education: Full service schools. Pretoria: Government Printers. 
Department of Education. (2006). Conceptual and operational guidelines for implementation of inclusive education: Special schools as resource centres. Pretoria: Government Printers.

Eastern Cape Department of Education. (2008). A resource pack for accommodating learners experiencing barriers to learning. Bisho: Government Printers

Engelbrecht, P. (2006). The implementation of inclusive education in South Africa after ten years of democracy. European Journal of Psychology of Education, XXI(3).

Engelbrecht, P., Oswald, M., \& Forlin, C. (2006). Promoting the implementation of inclusive education in primary schools in South Africa. British Journal of Special Education, 33(3).

Engelbrecht, P. (2003). External evaluation of the SCOPE component: Introducing inclusive education. Unpublished research report for SCOPE and Department of Education.

Faller, F. (2005). Yes, there is a crisis in teacher supply: Teaching times for education. Johannesburg: Printability.

Hay, J.F. (2003). Implementation of inclusive education paradigm shift in South African education support services. South African Journal of Education, 23(2).

Howell, C. (2007). Learners with special needs. Cape Town: University of the Western Cape.

Howell, C. \& Lazarus, S. (2003). Access and participation for students with disabilities in South African higher education: Challenging accepted truths and recognizing new possibilities. Perspectives in Education, 21(3).

Landsberg, E.J. et.al. (Eds.). (2005). Addressing barriers to learning: A South African perspective. Pretoria: Van Schaik.

Lauer, P.A. (2006). An educational research primer: How to understand, evaluate and use it. Jossey-Bass.

Louis, C., Manion, L.M., \& Morrison, K. (2007). Research in education (6th ed.). London: SAGE.

McMillan, J.H. (2008). Educational research: Fundamentals for the consumer. Boston: Pearson.

McMillan, J.H. \& Schumacher, S. (2006). Research in education: Evidence based inquiry (6th ed.). Boston: Pearson.

Ngcongo, G.P. \& Chetty, K. (2006). Issues in school management and governance. Cape Town: Juta \& Company.

Republic of South Africa (RSA). (1996). South African School's Act, No. 84. Government Printers.

Republic of South Africa (RSA). (1996). CONSTITUTION OF THE REPUBLIC OF SOUTH AFRICA NO. 108 OF 1996. Government Printers: Pretoria

Stofile, S. \& Green, L. (2006). Inclusive education in South Africa. In P Engelbrecht \& L Green (Eds.), Responding to challenges on inclusive education in Southern Africa. Pretoria: Van Schaik.

Stofile, S. (2008). Factors affecting the implementation of inclusive education policy: A case study in one province of South Africa. Cape Town: University of Cape Town.

Swart, S. \& Pettipher, R. (2007). Changing roles of principals and educators. Pretoria: Van Schaik.

Wildeman, R.A. \& Nomdo, C. (2007). Implementation of inclusive education: How far are we? Report to IDASA on 7 March 2007. Retrieved from http://www.org.za. 